\title{
MIMOC: A global monthly isopycnal upper-ocean climatology with mixed layers
}

\author{
Sunke Schmidtko, ${ }^{1,2}$ Gregory C. Johnson, ${ }^{1}$ and John M. Lyman ${ }^{1,3}$ \\ Received 23 November 2012; revised 7 February 2013; accepted 8 February 2013; published 3 April 2013.
}

[1] A monthly, isopycnal/mixed-layer ocean climatology (MIMOC), global from 0 to $1950 \mathrm{dbar}$, is compared with other monthly ocean climatologies. All available qualitycontrolled profiles of temperature $(T)$ and salinity $(S)$ versus pressure $(P)$ collected by conductivity-temperature-depth (CTD) instruments from the Argo Program, Ice-Tethered Profilers, and archived in the World Ocean Database are used. MIMOC provides maps of mixed layer properties (conservative temperature, $\Theta$, absolute salinity, $S_{A}$, and maximum $P$ ) as well as maps of interior ocean properties $\left(\Theta, S_{A}\right.$, and $\left.P\right)$ to $1950 \mathrm{dbar}$ on isopycnal surfaces. A third product merges the two onto a pressure grid spanning the upper $1950 \mathrm{dbar}$, adding more familiar potential temperature $(\theta)$ and practical salinity $(S)$ maps. All maps are at monthly $0.5^{\circ} \times 0.5^{\circ}$ resolution, spanning from $80^{\circ} \mathrm{S}$ to $90^{\circ} \mathrm{N}$. Objective mapping routines used and described here incorporate an isobath-following component using a "Fast Marching" algorithm, as well as front-sharpening components in both the mixed layer and on interior isopycnals. Recent data are emphasized in the mapping. The goal is to compute a climatology that looks as much as possible like synoptic surveys sampled circa 2007-2011 during all phases of the seasonal cycle, minimizing transient eddy and wave signatures. MIMOC preserves a surface mixed layer, minimizes both diapycnal and isopycnal smoothing of $\theta-S$, as well as preserves density structure in the vertical (pycnoclines and pycnostads) and the horizontal (fronts and their associated currents). It is statically stable and resolves water mass features, fronts, and currents with a high level of detail and fidelity.

Citation: Schmidtko, S., G. C. Johnson, and J. M. Lyman (2013), MIMOC: A global monthly isopycnal upper-ocean climatology with mixed layers, J. Geophys. Res. Oceans, 118, 1658-1672, doi:10.1002/jgrc.20122.

\section{Introduction}

[2] An accurate description of the mean state of the ocean is a long-time goal of oceanographic science. Global- to basin-scale surveys of ocean water properties were initiated over a century ago, with the famous global expedition of the Challenger in the 1870s [Murray, 1885] followed by the Fram expedition towards the North Pole from 1893 to 1896 [Nansen, 1900], the Discovery expeditions to the Antarctic from 1924 to 1931 [Deacon, 1937], the Meteor expedition of the South Atlantic from 1925 to 1927 [e.g., Wüst and Defant, 1936], the extensive Atlantic surveys associated with the International Geophysical Year in 1957-1958 [e.g., Fuglister, 1960], the work on the Eltanin in the Southern

\footnotetext{
${ }^{1}$ Pacific Marine Environmental Laboratory, National Oceanic and Atmospheric Administration, Seattle, Washington, USA.

${ }^{2}$ School of Environmental Sciences, University of East Anglia, Norwich, UK.

${ }^{3}$ Joint Institute for Marine and Atmospheric Research, University of Hawaii at Manoa, Honolulu, Hawaii, USA.

Corresponding author: S. Schmidtko, School of Environmental Sciences, University of East Anglia, Norwich, NR4 7TJ, UK. (s.schmidtko@uea.ac.uk)

(C)2013. American Geophysical Union. All Rights Reserved. 2169-9275/13/10.1002/jgrc.20122
}

Ocean in the 1960s [e.g., Gordon, 1966; Pytkowicz, 1968], and the global GEOSECS survey during the 1970s [e.g., Bainbridge, 1976], to name several.

[3] A recent and comparatively comprehensive milestone in global ocean water property exploration was the one-time hydrographic survey conducted as part of the international World Ocean Circulation Experiment (WOCE) during the 1980s and 1990s [e.g., King et al., 2001]. This monumental effort gathered measurements of a number of different water properties with very high accuracy and high vertical and along-track resolution from the ocean surface to its floor, with the global ocean sampled by a grid-like pattern of coast-to-coast tracks. However, the effort, ship time, and hence expense required for such surveys necessitated gaps between tracks, and seasonal coverage was largely lacking (most of the tracks were only visited once, usually not in winter - only a few hardy scientists elect to work in, for instance, the Labrador Sea in February). Still, this data set affords very useful three-dimensional information on ocean water properties and comprises a global baseline of late twentieth-century ocean conditions.

[4] The Argo Program, with more than 3000 active, fully autonomous profiling floats each collecting and reporting a CTD (conductivity-temperature-depth instrument) profile between the surface and a target pressure of $2000 \mathrm{dbar}$, nominally every 10 days, provides high-quality, spatially and 
temporally distributed sampling of temperature and salinity in the global ice-free ocean [Roemmich et al., 2009]. This program started in 2000, first achieved sparse global coverage by around 2004 or 2005, and reached its 3000 active float target in late 2007. Floats also now sample under seasonal sea ice [Klatt et al., 2007], and Ice-Tethered Profilers (ITPs) [Toole et al., 2011] provide data under perennial Arctic sea ice. This near-global, year-round, high-quality sampling of the upper half of the ocean volume for both temperature and salinity is revolutionary for observational physical oceanography.

[5] As oceanographic data have become more plentiful and better resolved, more ocean climatologies and atlases have been constructed (e.g., Table 1). We compare our results to three isobar-averaged global (or near-global) and monthly products: the World Ocean Atlas 2009 (WOA09) [Locarnini et al., 2010; Antonov et al., 2010], the 2009 CSIRO Atlas of the Regional Seas (CARS09) [Ridgway et al., 2002], and the Argo-based Marine Atlas (AMA) [Roemmich and Gilson, 2009]. WOA09 is a monthly atlas mapped on isobars. CARS09, also an isobaric atlas, provides a mean, annual, and semiannual harmonics; takes topography into account; and uses adaptive smoothing scales. Both WOA09 and CARS09 use all available data to estimate a mean seasonal cycle. Because of the irregular sampling of oceanographic data in the past, they can be termed mixedera climatologies. AMA uses Argo data only and has monthly maps for individual years starting in January 2004. Since the climatology presented here also represents the mean seasonal cycle, for AMA we average all the years for a given month prior to comparisons. Climatologies averaged on isopycnals also exist, but one is solely a multi-year mean (hereafter WGHC) [Gouretski and Koltermann, 2004] and another is really a data set and software tool (hereafter Hydrobase) [Lozier et al., 1995; Curry, 1996]. Hence, we make a limited comparison of our results to WGHC and none to Hydrobase.

[6] Here we construct a global ocean climatology from 0 to $1950 \mathrm{dbar}$, the Monthly Isopycnal/Mixed-layer Ocean Climatology (MIMOC), combining different features of previous efforts and adding a few new features (Table 1).
Interior ocean properties are mapped on isopycnals, much like WGHC and Hydrobase, and those fields are provided. However, we also map surface mixed layer properties, which are also provided. Finally, we merge the mixed layer maps with those of the interior properties on isopycnals onto a regular pressure grid.

[7] We employ a topography-following mapping scheme, somewhat like CARS09 but using a different algorithm, and add an equatorial latitudinal damping term to reflect the more zonal hydrographic structures near the equator. We also include front-sharpening weighting schemes within the ocean interior and in the mixed layer. Finally, we focus on the best sampled era, 2007-2011, where possible, supplemented by historical CTD data. Historical data are given a lower signal-to-noise ratio to discount them where sufficient recent data exist but to allow their use in the maps where recent data are sparse, especially in some marginal seas, at high latitudes, and near the coasts (including on continental shelves).

[8] Immediately following this introduction, the data are discussed. Subsequently, the methods used to generate MIMOC are presented first in summary and then individually-motivated by targeted comparisons with other climatologies. After this presentation, we discuss one area that could still benefit from improvement-joining the mixed layer to the interior isopycnals in regions of strong gradients. Conclusions follow.

\section{Data}

[9] This climatology uses CTD profiles from three sources: Argo floats [e.g., Roemmich et al., 2009], ITPs [Toole et al., 2011], and shipboard data from the World Ocean Database 2009 (hereafter WOD) [Boyer et al., 2009]. Except in a few isolated regions, Argo CTD data are the main data contributor in the open ocean, and ITPs are contemporaneous contributors in the Arctic (compare Figures $1 \mathrm{~b}$ and 1c). Since Argo does not yet sample continental shelves, some marginal seas, or most ice-covered regions, attempts to map the global oceans must include shipboard data. Since the sampling periods of shipboard

Table 1. Parameters of Climatologies Compared in This Study

\begin{tabular}{|c|c|c|c|c|}
\hline & \multicolumn{4}{|c|}{ Climatology Name } \\
\hline & WOA09 & CARS09 & AMA & MIMOC \\
\hline Mapping surfaces & isobaric & isobaric & isobaric & isopycnal and mixed layer \\
\hline $\begin{array}{l}\text { Vertical level count } \\
\text { (to } 1950 \mathrm{dbar}^{\mathrm{a}} \text { ) }\end{array}$ & $40(24)$ & $79(65)$ & $58(57)$ & $81(81)^{\mathrm{b}}$ \\
\hline Horizontal resolution & $1^{\circ} \times 1^{\circ}$ & $0.5^{\circ} \times 0.5^{\circ}$ & $0.5^{\circ} \times 0.5^{\circ}$ & $0.5^{\circ} \times 0.5^{\circ}$ \\
\hline Max. depth (with seasonal & $5500 \mathrm{~m}$ & $5500 \mathrm{dbar}$ & 1975 dbar & $1950 \mathrm{dbar}$ \\
\hline cycle) & $(1500 \mathrm{~m})$ & $\left(1800 \mathrm{dbar}^{\mathrm{c}}\right)$ & (1975 dbar) & (1950 dbar) \\
\hline Mapping method & multi-pass Gaussian smoothing & LOESS & objective analysis & objective analysis \\
\hline $\begin{array}{l}\text { Covariance shape, } \\
\text { bathymetry influence } \\
\text { on mapping }\end{array}$ & $\begin{array}{l}\text { circular, regional boundaries } \\
\text { between basins }\end{array}$ & $\begin{array}{l}\text { CSIRO-BAR filter (ellipse } \\
\text { along bathymetry) }\end{array}$ & $\begin{array}{l}\text { distance penalty for } \\
\text { profiles over varying } \\
\text { topography }\end{array}$ & $\begin{array}{l}\text { path finding algorithm } \\
\text { using median filtered } \\
\text { ETOPO-1 }\end{array}$ \\
\hline Mixed layer & $\begin{array}{l}\text { none, separate climatology } \\
\text { available }\end{array}$ & $\begin{array}{l}\text { none, separate climatology } \\
\text { available }\end{array}$ & none & $\begin{array}{l}\text { included, separate } \\
\text { climatology available }\end{array}$ \\
\hline Variables mapped & $T, S$, and biogeochemical & $\begin{array}{l}T, S, \text { and limited } \\
\text { biogeochemical }\end{array}$ & $T$ and $S$ & $\theta$ and $S, \Theta$ and $S_{A}$ \\
\hline
\end{tabular}

${ }^{\mathrm{a}}$ WOA09 uses depth for the vertical coordinate, so $1950 \mathrm{~m}$ is used as its break point.

${ }^{\mathrm{b}}$ Also available for the mixed layer and on selected isopycnal surfaces.

${ }^{\mathrm{c}}$ Mean, annual, and semiannual harmonics from 0 to $1000 \mathrm{dbar}$, mean and annual harmonics from 1000 to $1800 \mathrm{dbar}$, mean only below $1800 \mathrm{dbar}$. 

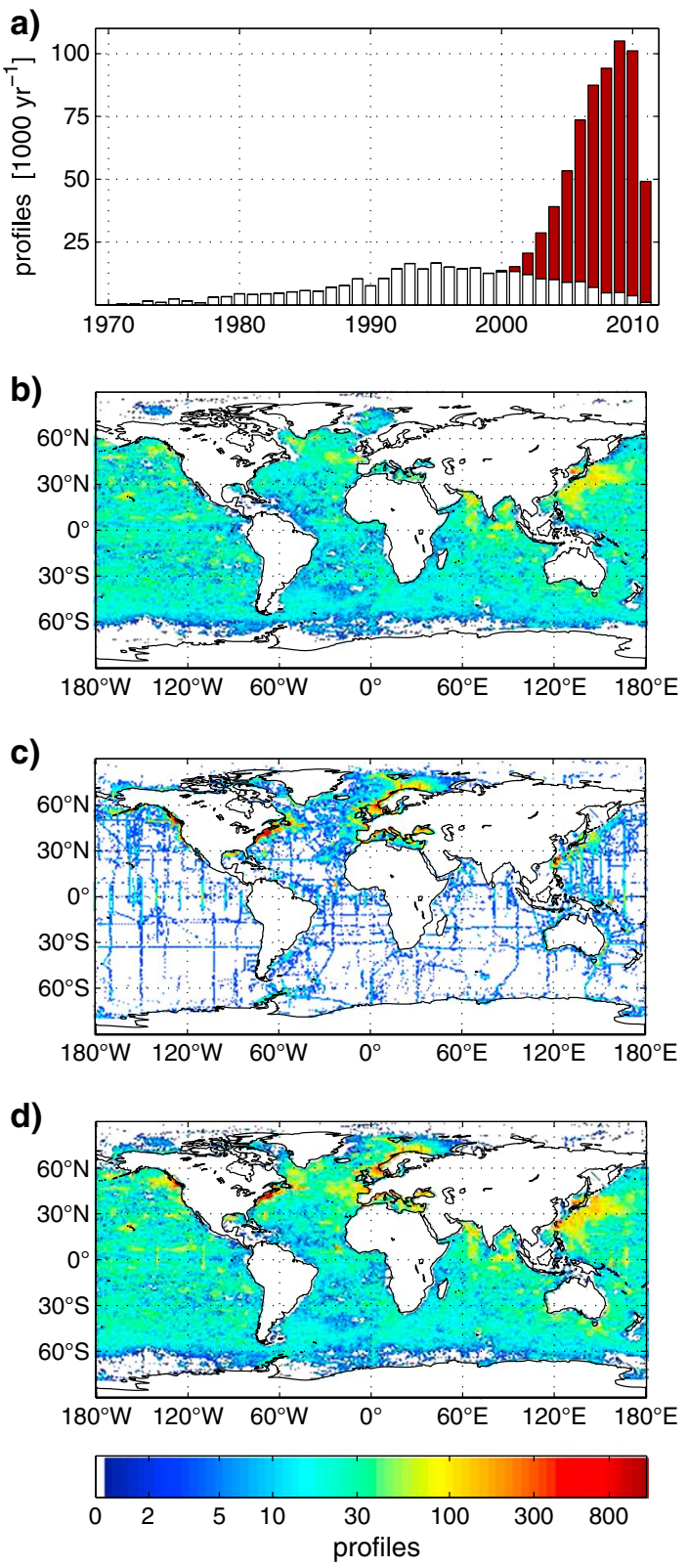

Figure 1. Data distribution for MIMOC. (a) Temporal distribution of CTD profiles from WOD (white) and Argo/ITP profiles (red). (b) Spatial distribution of Argo and reduced ITP profiles (see text) for each $1^{\circ} \times 1^{\circ}$ grid box in logarithmic colors. (c) Same as Figure 1b but for WOD profiles. (d) Same as Figure 1b but for Argo, reduced ITP, and WOD profiles combined.

compared to Argo and ITPs are vastly different (Figure 1a), temporal sampling bias in mapping shelf regions and some marginal seas vs. the open oceans is unavoidable.

[10] All Argo float profiles from an Argo global data assembly center as of January 2012 that have a quality control (QC) flag 2 or better are used, employing adjusted (delayed-mode) variables as available ( $>680,000$ profiles, Figures $1 \mathrm{a}$ and $1 \mathrm{~b}$ ). WOD CTD profiles available as of January 2012 are used if quality flags are 0 or 2; profiles have monotonically increasing pressure, at least 20 vertical measurements spaced less than $12 \mathrm{dbar}$ apart; and the maximum pressure is larger than the shallower of $200 \mathrm{dbar}$ from the bottom or $1500 \mathrm{dbar}$ ( $>415,000$ profiles, Figures 1a and 1c). These last criteria are imposed to avoid introducing biases or discontinuities in the maps that arise when combining numerous shallow profiles (say to $1000 \mathrm{dbar}$, a common profiling pressure) with deeper ones, as discussed in section 3.1. Bathymetry data used for this quality control step and within the mapping process in the following are the ETOPO-1 data sets [Amante and Eakins, 2009]. ITP profiles processed to level 3 as of May 2011 are used $(>18,000$ profiles). For each week of ITP data from each instrument, the median parameters on each isopycnal surface are used to reduce the number of profiles, which are collected at a higher-than-daily frequency. No further quality control is applied to ITP data since this data set is very well quality controlled. In all instances, temperature $(T)$ and salinity $(S)$ must both be available at a given reported pressure $(P$, or depth) level to be included (ITP profiles are included with the Argo float data in Figure 1).

[11] While this basic, initial data screening benefits from the efforts of groups involved with WOD, Argo, and ITP, it might be deemed minimal compared to the rigorous, labor-intensive visual quality control effort applied to the data sets for some climatologies, e.g., Hydrobase. Our quality control relies instead on a robust mapping algorithm including the removal of outliers via statistical filters and automatic downweighting of data points with unusual water mass properties that pass through these filters.

\section{Methods: Constructing the Climatology}

[12] Constructing MIMOC is fairly involved, so we outline the process here before delving into detail. First, the profiles are prepared, with water properties derived and interpolated onto isopycnal surfaces. We compute properties of the mixed layer using the density algorithm of Holte and Talley [2009]. Then, data near each grid point are selected, and outliers are found and discarded as detailed below. Distance from the grid point includes consideration of fronts (data on the other sides of fronts are considered farther away) and bathymetry (along-isobath distances are considered closer than across-isobath distances using a fast marching algorithm, and land barriers are respected). Mean properties weighted by distance are generated as a first guess prior to objective mapping. Pre-2007 data are de-emphasized in the objective maps by increasing their noise-to-signal energy in the mapping. Objective maps of water properties in the mixed layer and on isopycnals in the ocean interior are generated. These maps are lightly low-pass filtered and gaps are filled. Spice-preserving adjustments are made to $\Theta$ and $S_{A}$ to compensate for effects of artificial mixing (smoothing) in the presence of a nonlinear equation of state. The mixed layer and interior isopycnal maps, both products themselves, are also merged onto a set of standard pressures to make a third product.

\subsection{Profile Preparation}

[13] For each individual profile, conservative temperature, $\Theta$, absolute salinity, $S_{A}$, and surface-referenced potential density anomaly, $\sigma_{0}$, are calculated using v3.0 of the 2010 TEOS equation of state [IOC, SCOR and IAPSO, 2010; T. J. McDougall et al., manuscript in preparation, 2012]. 
Neutral density, $\gamma_{\mathrm{n}}$, cannot be used in the construction, since the climatology is global, including marginal seas where neutral density is not defined [McDougall and Jackett, 2005]. The mixed layer $S_{A}, \Theta, \sigma_{0}$, and depth (hereafter mixed layer pressure, MLP, since pressure is used here as the vertical coordinate) are computed using the Holte and Talley [2009] density algorithm. If the algorithm fails to provide a MLP (e.g., when $P>20$ dbar for the shallowest measurement), the profile is removed from the data set.

[14] As a quality control measure, any profiles with density inversions $>0.06 \mathrm{~kg} \mathrm{~m}^{-3}$ between two vertically adjacent measurements are discarded. This threshold is twice the Argo real-time quality control test for inversions. These relatively small density inversions are tolerable and assumed to originate from measurement inaccuracies or truncation errors. Of the 680,000 float profiles that pass QC, 470,000 have inversions $<0.06 \mathrm{~kg} \mathrm{~m}^{-3}$. These are mitigated by re-ordering raw profiles by density.

[15] Following these steps, $S_{A}, \Theta$, and $P$ for each profile are linearly interpolated vertically onto 550 fixed $\sigma_{0}$ surfaces, without extrapolation. The surfaces chosen are a compromise between reasonable computation time and file sizes versus adequate vertical resolution throughout the global ocean and marginal seas, with their large regional variations in vertical distribution of $\sigma_{0}$. The first 389 isopycnal surfaces are distributed in nine linear subsets with decreasing $\sigma_{0}$ intervals from $-1 \leq \sigma_{0} \leq 27.938 \mathrm{~kg} \mathrm{~m}^{-3}$. The last 161 isopycnals in four subsets are again linearly spaced from $27.94 \leq \sigma_{0} \leq 29.44 \mathrm{~kg} \mathrm{~m}^{-3}$, but with varying $\sigma_{0}$ intervals to span the dense waters in the Nordic and Mediterranean seas.

[16] Where isopycnals outcrop at the surface or at the bottom, the mapping algorithm only has data on one side, spatially or temporally. For isobaric mapping, this problem is limited to near bathymetry. This situation leads to maps biased toward interior ocean values close to the surface and the bottom.

[17] To overcome this bias at the surface, profiles with denser mixed layers are extended with lighter isopycnal values at pressure 0 . Here $\Theta$ and $S_{A}$ are filled with LOWESS-mapped (robust LOcally Weighted regrESSion) [Cleveland, 1981] $\Theta$ and $S_{A}$ using the closest 30 profiles in density space on either side of the isopycnal being filled. The LOWESS maps fit a mean as well as a plane in density, seasonal time, virtual latitude, and virtual longitude. The weights used are those used for computing the respective monthly mixed layer for the grid point, but with a floor set at 0.05 to ensure the plane fitting is not overly influenced by spatiotemporally close but variable data. This method prevents isopycnals directly below the mixed layer from being mapped based on data from the ocean interior alone and allows isopycnal mapping up to the mixed layer, without switching to isobaric mapping in the upper ocean as done in other isopycnal climatologies such as the WGHC that uses isobaric mapping for the upper $100 \mathrm{dbar}$.

[18] At our maximum mapping pressure of $1950 \mathrm{dbar}$, Argo floats sporadically sample higher densities due to internal waves, leading to a bias toward shallower pressure values in the isopycnal maps. Fronts at this depth are not as pronounced as those at the surface; thus, we use a simple objective mapping to make a best guess $\Theta$ and $S_{A}$ approximation. $P$ is extrapolated by using the weighted mean $\Delta P / \Delta \sigma_{0}$ from profiles reaching deeper, using the identical weights as for the main MIMOC computation discussed below, but without the temporal term. For $\Theta$ and $S_{A}$, data are handled similarly to the final mapping described below, with statistical outliers removed in $S_{A}, P$, and $\Theta$, a front-finding algorithm in $P$ applied and weighted means of the data used as first guess for the objective maps. Finally, objective mapping is performed with the same decadal downweighting with noise as detailed below. $P$ is not extended vertically in the same step as $\Theta$ and $S_{A}$ since $\Delta P / \Delta \sigma_{0}$ requires the next denser isopycnal to be available in a profile as well, so doing so would further limit the data available for $\Theta$ and $S_{A}$.

\subsection{Data Selection and Objective Mapping}

[19] All objective maps are global from the Antarctic shelf to the North Pole and made at monthly $0.5^{\circ} \times 0.5^{\circ}$ lateral resolution, covering all areas with water depth $>10 \mathrm{~m}$ according to ETOPO-1. The objective mapping procedure used is standard [e.g., Bretherton et al., 1976] but with three innovations, each explained in the subsections that follow. One innovation is the use of a fast marching algorithm to transform distance coordinates based on the bottom topography and the presence of the equator, reducing smoothing across isobaths and the equator and preventing smoothing across land. This innovation is foreshadowed immediately below by the term "along-pathway distance." A second innovation is additions to the weighting and covariance functions that sharpen fronts in both the mixed layer and the ocean interior, also explained later. A third innovation is an addition to the diagonal of the covariance matrix that de-emphasizes data prior to 2007 in the objective maps.

[20] For the mixed layer, we map $\sigma_{0}, \Theta, S_{A}$, MLP, year values, and a formal error. On $\sigma_{0}$ surfaces in the ocean interior, we map $\Theta, S_{A}, P, \sigma_{0}$, year, and formal error. In addition, we also iteratively generate weighted means, as described below, for all these quantities. These weighted means are used as first guesses for the objective maps and are comparatively smooth. They may be useful for work that requires that characteristic. For the mixed layer and pressure-gridded products, we compute potential temperature, $\theta$, and practical salinity, $S$, from $\Theta$ and $S_{A}$.

[21] The closest 2250 profiles within $2000 \mathrm{~km}$ of the along-path distance from each grid point (regardless of month) are used for mapping at that grid point. If there are less than 2250 profiles in this radius, then all are used, but data from more than five profiles must be found to attempt a map for a grid point. If five or fewer profiles are available for a grid point, it is ignored in the objective mapping but filled by lateral interpolation (or extrapolation) when constructing the final products as detailed below. The initial weighting function (accounting for along-path distance and time of the year) is assigned a conventional Gaussian form:

$$
w_{i}=\exp \left\{-\left[\left(\frac{\Delta t}{L_{t}}\right)^{2}+\left(\frac{\Delta d_{x}}{L_{x}}\right)^{2} 2\right]\right\},
$$

where $\Delta t$ is the temporal difference between the month being mapped and that of the data value (circular, disregarding the year), $L_{t}$ is the temporal decorrelation scale of 45 days, $\Delta d_{x}$ is the along-path distance between the grid point and the data sample, and $L_{x}$ is the lateral decorrelation scale of $330 \mathrm{~km}$. 
[22] For each month, the 300 profiles with the highest weights and 200 more random profiles from the next highest-weighted 1500 profiles are selected from the 2250 points mentioned above. The number of data points used and their selection method are compromises that balance available computational time and accurate mapping; they provide sufficient data for the mapping algorithm to map the local properties and their gradients in the larger area. A floor of $\varepsilon=10^{-6}$ is set for a new, modified weighting function, $\boldsymbol{W}_{i}=\boldsymbol{w}_{i} \cdot(1-\varepsilon)+\varepsilon$. This floor mitigates problems that arise from rounding errors.

\subsection{Removing Outliers}

[23] Prior to computing the maps, we discard outliers using an interquartile range (IQR) filter. The IQR is simply the third minus the first quartile. Here outliers are defined as being more than twice the IQR below the first quartile or more than twice the IQR above the third quartile. This cutoff is analogous to retaining data within 2.7 standard deviations on either side of the mean, or $>99.9 \%$ of the data, for a normal distribution. In the mixed layer, this filter is applied to $\sigma_{0}$ and MLP values. On interior isopycnals, this filter is applied to $P$ and $S_{A}$. Since $S_{A}$ and $\Theta$ are very highly correlated on isopycnals, application of the filter to $\Theta$ would be redundant.

\subsection{Sharpening Fronts and Downweighting Remaining Outliers}

[24] One modification to the weighting and covariance functions prior to mapping the data is designed to sharpen fronts. For the mixed layer, the weighted standard deviation for $S_{A}$ and $\Theta$ are computed and used in a term added to the weighting and covariance functions, so

$\omega_{i}=\exp \left\{-\left[\left(\frac{\Delta t}{L_{t}}\right)^{2}+\left(\frac{\Delta d_{x}}{L_{x}}\right)^{2}+\left(\frac{\Delta S_{A}}{1.2 \cdot \sigma_{S_{A}}}\right)^{2}+\left(\frac{\Delta \Theta}{1.2 \cdot \sigma_{\Theta}}\right)^{2}\right]\right\}$,

where $\Delta \Theta$ is the difference between each observed $\Theta$ and the locally weighted mean $\Theta$ calculated using the weight vector $\boldsymbol{W}$ with the weights $\boldsymbol{W}_{i} ; \Delta S_{A}$ is defined analogously. As above, a floor of $10^{-6}$ is set for all elements of $\boldsymbol{\omega}_{i}$, and the result is used to compute a local weighted mean at each grid point for all of the properties to be mapped (including $\left.\sigma_{0}\right)$. This algorithm sharpens density fronts in the mixed layer. The factor of 1.2 is chosen to optimize the results based on visual examination of differences between the mixed layer mapping and the uppermost mapped isopycnal. These weights are then used to recompute the local weighted mean in $S_{A}$ and $\Theta$, which are thereafter used in the above equation for $\boldsymbol{\omega}_{\boldsymbol{i}}$ to compute the final set of weights.

[25] The advantage of using $\Theta$ and $S_{A}$ rather than $\sigma_{0}$ for front sharpening in the mixed layer is to resolve thermal and haline gradients that are density compensated as they are within the mixed layer in many ocean regions [e.g., Rudnick and Ferrari, 1999]. Furthermore, MLP is not suitable for mixed layer front detection since it often exhibits very large and non-normal variability on short temporal and spatial scales.

[26] On $\sigma_{0}$ surfaces, we use $P$ for a single front-sharpening parameter, otherwise analogous to the procedure above. This is a dynamical front detector, sensitive to the large vertical excursions of $P$ on $\sigma_{0}$ across strong currents like the Gulf Stream, Kuroshio Extension, and Antarctic Circumpolar Current. This modification to the weighting and covariance functions tends to sharpen $\theta, S$, and $P$ gradients across these fronts, suppressing artificial mixing of water masses and making the mapped fields look more like a synoptic survey, which will generally find sharp fronts and strong currents. Furthermore, using $P$ for front sharpening on $\sigma_{0}$ surfaces reduces the weight of any erroneous measurement in $\Theta$, $S_{A}$, or $P$. The resulting strong interior gradients are clear from meridional sections (e.g., in the western South Atlantic, Figure 2) crossing the Antarctic Circumpolar Current (here near $50^{\circ} \mathrm{S}$ ) and the subtropical front (near $40^{\circ} \mathrm{S}$ ). In these locations, especially at the subtropical front, the meridional water property gradients in each of the other climatologies are much smoother than those in MIMOC, resulting in dipoles of water property anomalies of these climatologies with respect to MIMOC, especially pronounced at middepth, from 200 to $600 \mathrm{dbar}$ around the subtropical front. Synoptic meridional sections in this region (e.g., Figures $2 \mathrm{a}$ and 2b) [Tsuchiya et al., 1994] look much more like MIMOC in the strength of these fronts than do the other climatologies, except that the synoptic sections also contain prominent eddies that MIMOC does not retain.

\subsection{Covariance Matrix and De-emphasizing Pre-2007 Data}

[27] In addition to providing weighted means that are used as the first guess for the objective maps, the equations above are used to construct the covariance matrices for the objective maps, like the following for the mixed layer:

$$
E_{i j}=\exp \left\{-\left[\left(\frac{\Delta \mathrm{t}}{L_{t}}\right)^{2}+\left(\frac{\Delta d_{x}}{L_{x}}\right)^{2}+\left(\frac{\Delta S_{A}}{1.2 \cdot \sigma_{S_{A}}}\right)^{2}+\left(\frac{\Delta \Theta}{1.2 \cdot \sigma_{\Theta}}\right)^{2}\right]\right\} .
$$

[28] On isopycnals, the last two terms in (3) are replaced with $\left[|\Delta P| /\left(1.2 \cdot \sigma_{P}\right)\right]^{2}$; thus, instead of a Gaussian weighting by $\Theta$ and $S_{A}$, only a Gaussian weighting by $P$ is used. The difference between the weighting and the covariance matrices is as follows: In the former, the numerators of the three terms in the Gaussian are the differences between each parameter and the grid point time, location, and weighted mean front-sharpening parameter $\left(\Theta\right.$ and $S_{A}$ for the mixed layer and $P$ for $\sigma_{0}$ surfaces in the ocean interior). In the latter, the numerators are the difference in each parameter between the profiles $i$ and $j$.

[29] An estimate of noise-to-signal ratio is typically added to the diagonal of the covariance matrix prior to objective mapping. Here we use the form:

$$
E_{i i}=E_{i i}+\kappa_{0}+\kappa_{\text {decade }} \cdot\left\{1-\exp \left[-\left(\frac{\Delta y r}{\tau}\right)^{2}\right]\right\},
$$

where $E_{i i}$ is the diagonal of the covariance matrix $\boldsymbol{E}$ and $\kappa_{0}$ is a constant noise-signal ratio, set here to 1.5 . This value is chosen, again, by visual evaluation of test cases, this time optimizing between smoothness and feature resolution. Here our innovation is to use the noise to de-emphasize pre-2007 data in the objective maps. We set $\kappa_{\text {decade }}$ to 8.5 years, and $\Delta y r$ is the number of years prior to 1 January 2007 for each 

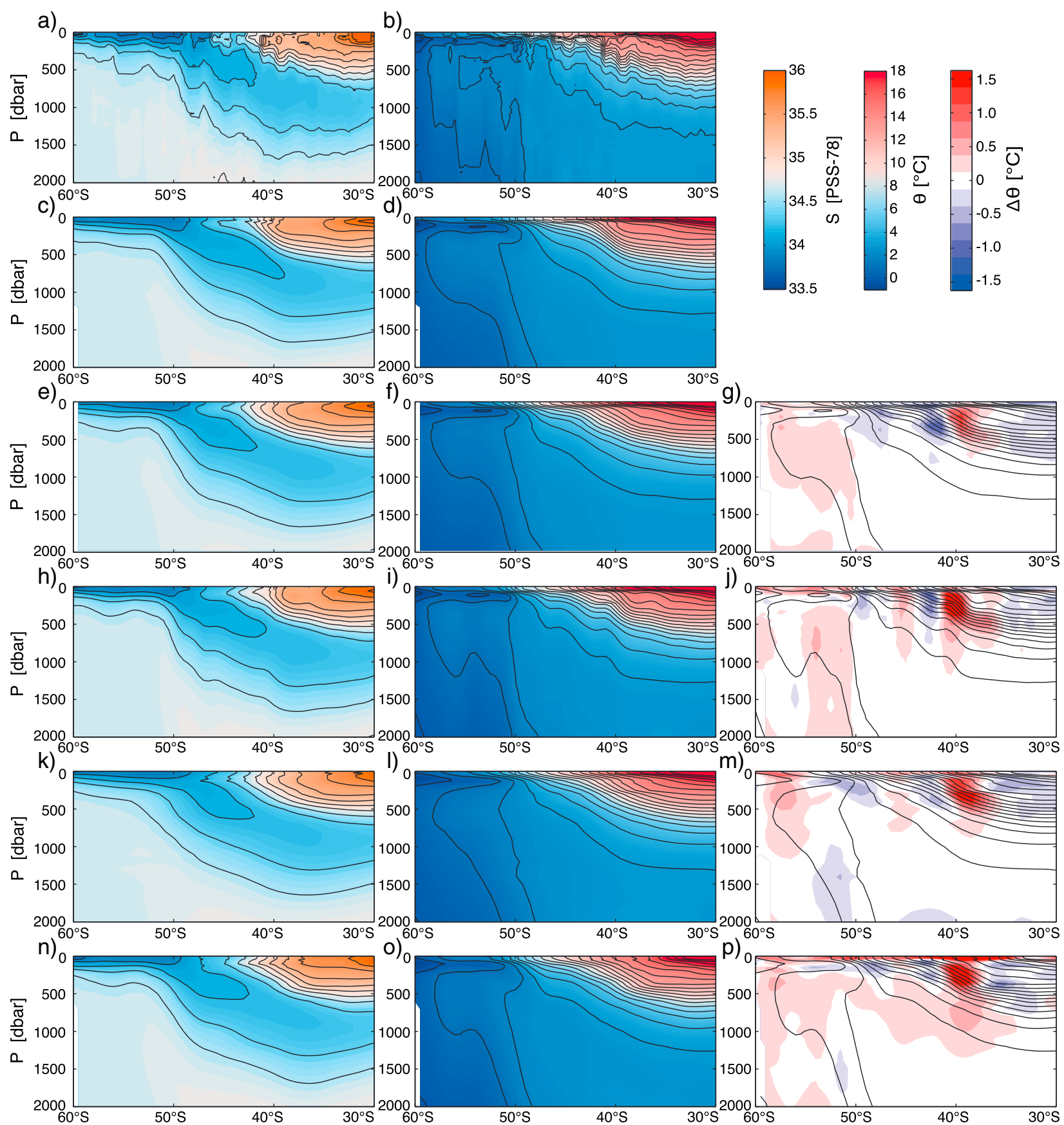

Figure 2. Meridional-vertical sections of (a) salinity $(S)$ and (b) potential temperature $(\theta)$ for WOCE A16 ${ }^{\circ} \mathrm{S}$ in the western South Atlantic Ocean January-February 2005 [e.g., Johnson and Doney, 2006 ]. Corresponding MIMOC sections for (c-d) $\theta$ and $S$ in January along $32.5^{\circ} \mathrm{W}$, similar for (e-f) AMA and (g) MIMOC minus AMA $\theta$ (colors) and for $(\mathrm{h}-\mathrm{j})$ CARS09, $(\mathrm{k}-\mathrm{m})$ WOA09, and (n-p) WGHC, with WGHC being an annual mean. Isohalines are contoured at 0.2 intervals and isotherms at $1{ }^{\circ} \mathrm{C}$ intervals for each climatology and the synoptic data (black lines).

data point. After that date, $\Delta y r$ is set to 0 . The time scale $\tau$ is set to 12 years. This formulation for the noise ensures that the objective maps are for modern conditions wherever modern data are available. However, the weighted means (which are used as the first guess for the map and to which the map relaxes in data-sparse regions) are a mixed-era average that includes historical CTD data (dating back to 1970). To make full use of the capabilities of objective mapping in the absence of recent data (since 2007), we set a floor of 1.5 for the noise-to-signal ratio. This floor ensures that in the sole presence of historic data, objective mapping does not relax toward the weighted mean too strongly.

[30] The influence of a modern climatology is apparent in areas which have undergone changes in water mass properties in recent decades, like the warming and shoaling of intermediate water masses [e.g., Schmidtko and Johnson, 
2012]. Weighting historical data in MIMOC less than in climatologies like CARS09 or WOA09 leads to warmer temperatures at $500 \mathrm{dbar}$ in MIMOC, especially in areas with abundant historic profiles, since MIMOC represents the modern state of the ocean rather than that of prior decades (Figures 1b, 1c, 3c, and 3d). AMA on the other hand, using only Argo data after 2004, is as warm as or even warmer than MIMOC (Figure 3b). Shelf regions and highlatitude regions with no ITP data lack the amount of recent data provided in the open ocean by Argo, thus are more representative of the state of the ocean before 2000 in MIMOC. MIMOC mapped years are available as an indicator of the local "vintage" of maps.

[31] At this point, objective mapping, also known as optimal interpolation, objective interpolation, or objective analysis, $b=\boldsymbol{\omega} \cdot \boldsymbol{E}^{-1} \cdot \boldsymbol{\psi}$, is performed on the anomalies of each parameter from its weighted mean. The spatial correlation scales and signal-to-noise levels used in constructing MIMOC maps are not determined from the data but
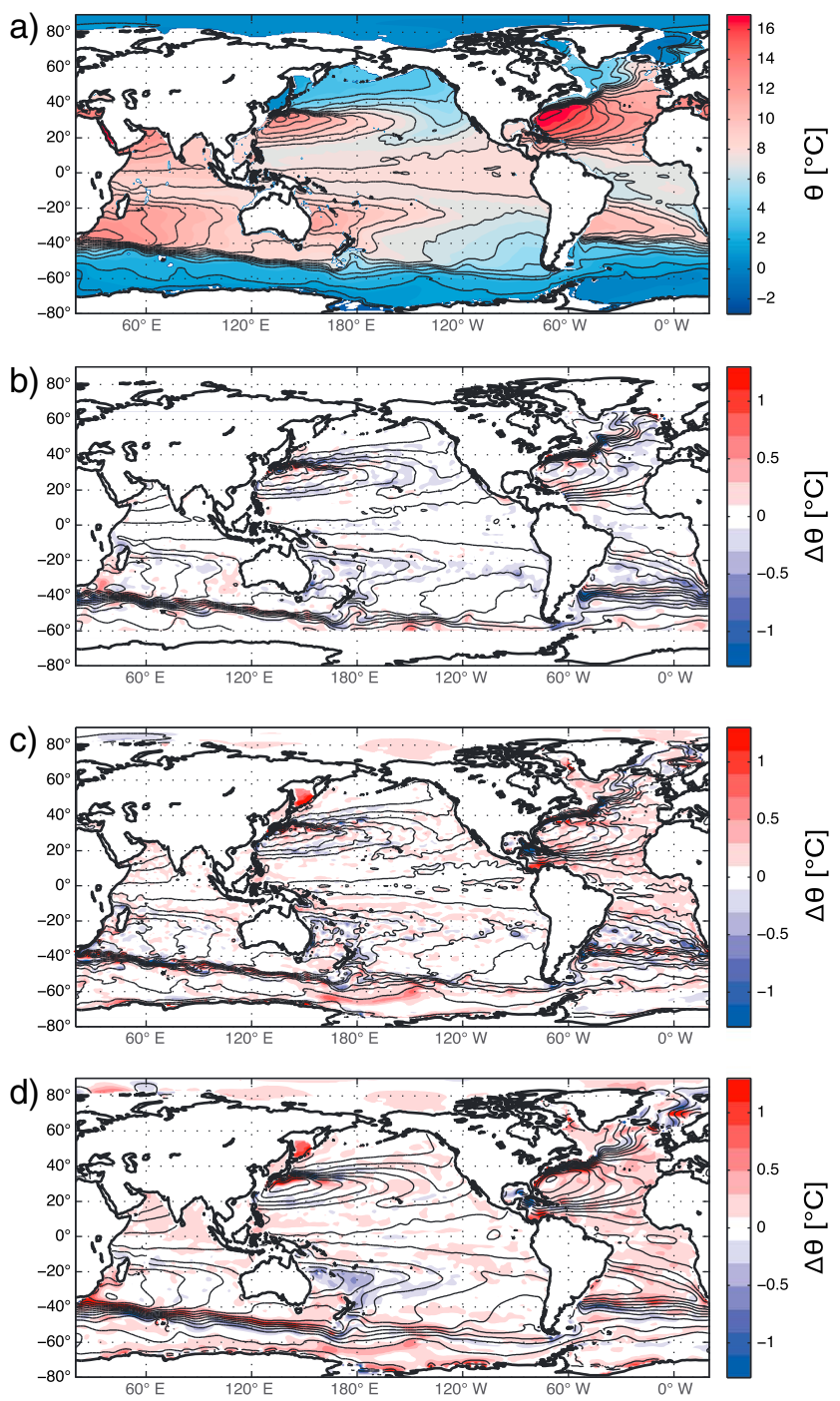

Figure 3. Maps of (a) MIMOC $\theta$ at 500 dbar in May and differences (MIMOC - each climatology) in color for (b) AMA, (c) CARS09, and (d) WOA09. Isotherms for each climatology are contoured at $1{ }^{\circ} \mathrm{C}$ intervals (black lines). prescribed, adding a subjective element to this procedure. Nonetheless, we refer to this operation as objective mapping hereafter. Here $\boldsymbol{\psi}$ is the vector of residuals of the measured properties and the weighted means, and $b$ is the objectively mapped anomaly. Values of the mapped properties are computed by adding the weighted means to the objectively mapped anomalies $b$. Formal errors are also estimated for the objective maps.

\subsection{Fast Marching: Taking Bathymetry and the Equator into Account}

[32] In the ocean, near-conservation of potential vorticity [e.g., Pedlosky, 1987] means that along-isobath decorrelation scales are much longer than cross-isobath ones, and especially in low latitudes, zonal decorrelation scales are much longer than meridional ones. Ocean currents also respect coastlines, with no flow into land. We construct an along-pathway distance to reflect the above constraints using the fast marching method [Sethian, 1996, 1999], which is based on the algorithm of Dijkstra [1959]. This method is often described in terms of wavefront propagation, as it solves the boundary value problem of the Eikonal equation, $\mathrm{SM}_{i}\left|\nabla t_{i}\right|=1$, where $t$ is the time and $\mathrm{SM}_{i}$ is the speed at each location in the normal direction of propagation. Hereafter SM is called the speed map. Here it is defined between 0 and 1 and represents the fraction of normal propagation speed. Thus, 0 effectively halts wavefront propagation at a grid point, and 1 allows normal speed wavefront propagation through a grid point.

[33] However, here we are really more interested in adjusting distances, so the time to reach grid points from the origin, the grid point being mapped, is here reinterpreted as distance. We determine a spatially varying speed map for each grid point being mapped with the form:

$$
\mathrm{SM}_{i}=\left[1-\left|\log \left(\frac{H_{0}}{H_{i}}\right)\right|\right] \cdot \exp \left[\left|\frac{\vartheta_{0}-\vartheta_{i}}{\exp \left(\frac{\vartheta_{0}}{7.5}\right)}\right|\right],
$$

where $H_{0}$ is the water depth at the grid point being mapped, $H_{i}$ are the water depths in nearby grid boxes $i$ in which data points might be located, $\vartheta_{0}$ is the latitude of the grid point being mapped, and $\vartheta_{i}$ are the latitudes of nearby grid boxes $i$. The depth for each grid point is determined by the median of all depths within the area of the grid box in the ETOPO1 data set. If more than two thirds of the area associated with a grid box is above the surface, the whole grid point is treated as land to ensure that narrow passages are closed to the mapping. Since (5) is very sensitive to changes in shallow water, $H_{0}$ and $H_{i}$ are set to a floor of $75 \mathrm{~m}$, which leads to a less sensitive speed map on the shelf.

[34] The speed map is unity in locations that have the identical depth and same latitude as the grid point to be mapped. The logarithmic term in (5) reduces the traveling speed through grid boxes with significant differences in water depth from the grid point being mapped. The exponential term reduces the speed through grid boxes that are at different latitudes than any grid point being mapped. The closer to the equator the grid point being mapped, the stronger is this effect. Thus, the first term creates a longer along-path distance than the Cartesian one for cross-isobath mapping, while the second term creates a longer distance than the Cartesian one for meridional mapping, more 
anisotropic nearer the equator. We set a floor of $\mathrm{SM}_{i}=0.05$ for any water-covered area, a maximum twentyfold increase in path distance. However, $\mathrm{SM}=0$ for grid points marked as land to prevent mapping pathways from crossing land. Hence, fast marching eliminates the necessity to define "hand-drawn" boundaries for mapping around peninsulas, basin boundaries, bays, and such.

[35] The fast marching algorithm does not retain the second dimension, but that information is necessary for objective mapping of fields with spatial gradients. Hence, we determine the angles at which the fast marching pathways must leave each grid point being mapped to reach each fast marching grid box via the minimum fast marching distance. These angles are then applied to the data along with the fast marching distances to effect a complete transformation from geographic to fast marching coordinates.

[36] The effectiveness of fast marching in separating ocean interior from shelf waters is well illustrated in the Bering Sea (Figure 4), where the Bering Slope Current [e.g., Johnson et al., 2004] is associated with a front between the interior ocean and the Bering Shelf. Here MIMOC (Figures $4 \mathrm{a}$ and $4 \mathrm{~b}$ ) exhibits a distinct separation of cold, fresh shelf waters and warmer, saltier waters

offshore that is blurred in some other climatologies (Figures 4c, 4d, 4e, and 4f). Also, in the southern half of the Bering Shelf, just as in synoptic sections [e.g., Coachman, 1986], MIMOC has the strongest $S$ gradient located right at the shelf break and the strongest $\theta$ gradient slightly northeast (landward) of the shelf break.

\subsection{Post-mapping: Smoothing and Infill}

[37] Mapped values at grid points with weight $<10^{-6}$ are removed to eliminate any remaining artifacts associated from round-off errors. After discarding these points from the maps, water properties in the mixed layer and on each interior ocean isopycnal surface are smoothed with a two-dimensional fifth-order binomial filter to reduce small-scale noise. This noise, likely owing to the fast marching algorithm, is on the order of $\pm 0.05^{\circ} \mathrm{C}$ in mixed layer temperatures and $< \pm 0.01{ }^{\circ} \mathrm{C}$ at pressures $>900 \mathrm{dbar}$. Water properties are also interpolated (and extrapolated) onto missing grid points with a spatial third-order binomial filter. These steps are performed iteratively, always smoothing or filling locations with a maximum of adjacent grid points first.

a)

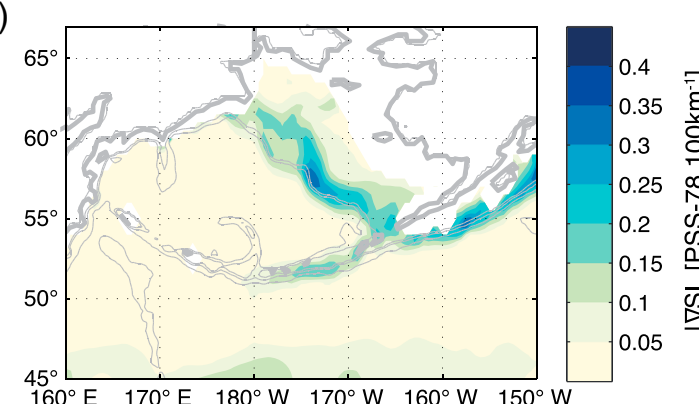

c)

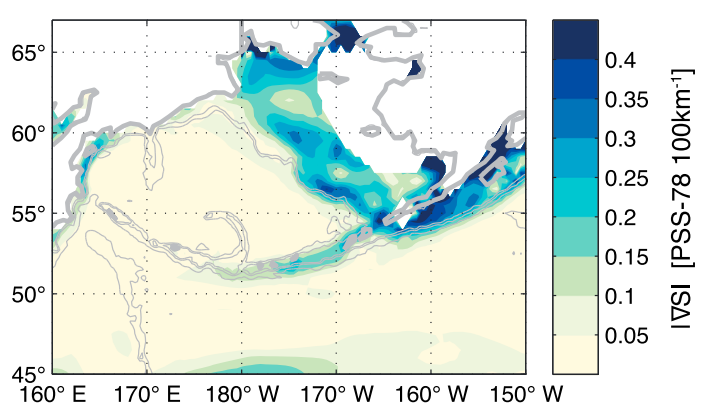

e)

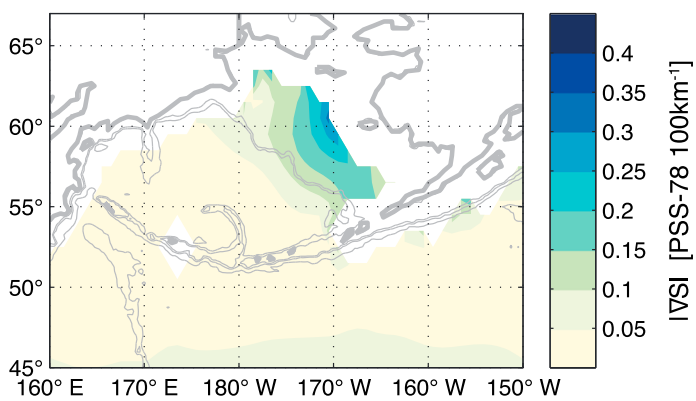

b)

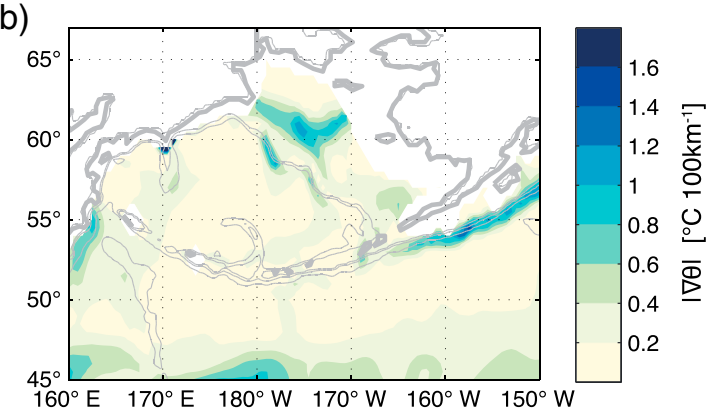

d)

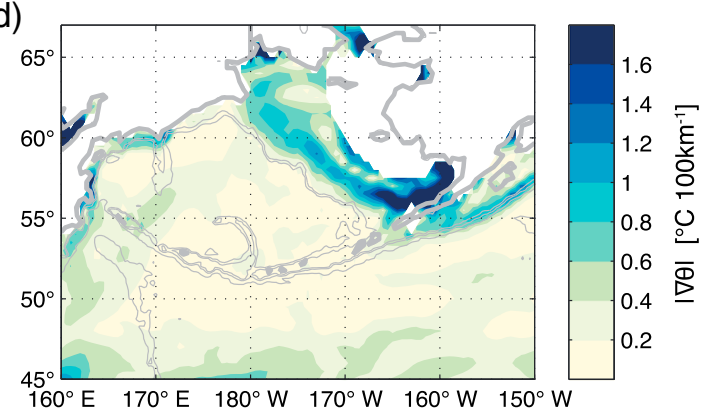

f)

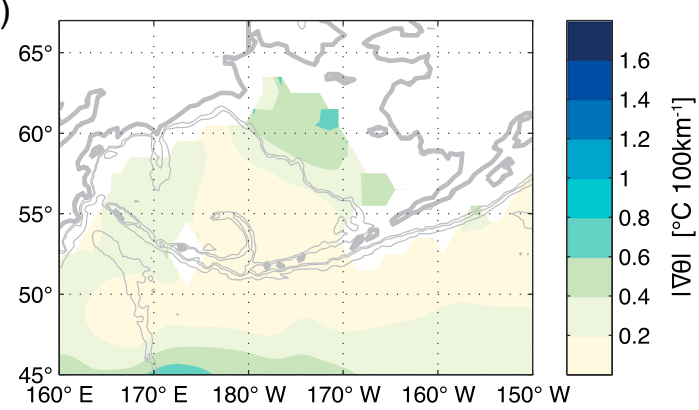

Figure 4. Maps of (left panels) $S$ and (right panels) $\theta$ gradients at $50 \mathrm{dbar}$ in the Bering Sea and Shelf for (a-b) MIMOC, (c-d) CARS09, and (e-f) WOA09. The coast (thick grey lines) and 1000, 2000, and $3000-\mathrm{m}$ isobaths (thin grey lines) are shown. The AMA climatology is omitted since it does not cover the Bering Sea or Shelf. 


\subsection{Cabbeling Biases}

[38] Because of the nonlinearity of the equation of state, waters of the same density and pressure but different $\Theta$ and $S_{A}$ (warmer-saltier versus colder-fresher) will always become slightly denser when mixed, a process called cabbeling [McDougall, 1987]. This process can create biases in density when mapping, because mapping explicitly smoothes (hence artificially mixes) $\Theta$ and $S_{A}$ data [e.g., Gille, 2004]. The result is that densities are generally greater (and sea level lower) when they are computed from mapped values rather than mapped themselves.

[39] The MIMOC fast marching and front-sharpening algorithms minimize smoothing of distinct water masses, but smoothing is part of constructing a climatology; in regions of strong fronts, the nonlinear mixing biases become noticeable. They are especially apparent when mapping on isopycnals because the density calculated from mapped $\Theta$ and $S_{A}$ values on an isopycnal is different (usually denser) than the initial isopycnal, especially in regions of strong $\Theta-S_{A}$ gradients (Figure 5).

[40] There are two possible responses to this problem: One can choose to conserve $\theta$ and $S$ and accept any (largely localized) increase in density, or one can adjust the mapped $\theta$ and $S$ values so they lie back on the initial isopycnal and conserve density. While conservation arguments support the former course, this is an isopycnal climatology, so we choose the latter. We further choose to conserve spiciness [e.g., Flament, 2002] in our adjustment, meaning that we make the water properties warmer and fresher in amounts so that $\Theta$ and $S_{A}$ changes contribute equally in terms of their contributions to density for the return to the initial isopycnal. Thus, additive adjustments $\Delta \Theta$ and $\Delta S_{A}$ are given by

$$
\begin{aligned}
\Delta \Theta & =\frac{\sigma_{0}\left(S_{\text {Amap }}, \Theta_{\text {map }}\right)-\sigma_{0 i}}{2 \alpha \rho_{0}} \text { and } \Delta S_{A} \\
& =\frac{\sigma_{0}\left(S_{\text {Amap }}, \Theta_{\text {map }}\right)-\sigma_{0 i}}{2 \beta \rho_{0}},
\end{aligned}
$$

where $\sigma_{0 i}$ is the initial isopycnal, $\Theta_{\text {map }}$ and $S_{A \text { map }}$ are the properties mapped, $\alpha$ is the local thermal expansion coefficient, and $\beta$ is the local haline contraction coefficient (Figure 5). The adjustments are everywhere sufficiently small that the local tangent to density (lines of constant spice) can be linearized. To be consistent, we make similar adjustments to $\Theta$ and $S_{A}$ for the mixed layer maps, using the mapped mixed layer density as a target for the adjustments.

[41] Some of the strongest nonlinear mixing biases found are in the western boundary currents and their extensions - where the warm salty waters of the subtropical gyres collide with the waters of the colder and fresher subpolar gyres. The North Atlantic Current is an extreme example (Figure 6). Even in the highest gradient regions of the upper reaches of this current between the gyres, the adjustments only reach about $+0.5^{\circ} \mathrm{C}$ for $\Theta$ and about -0.1 for $S_{A}$ (up to $+1.1^{\circ} \mathrm{C}$ and -0.16 PSS-78 on isolated grid points). If these biases were left in density, isopycnals in the core of the current would artificially shift about $20 \mathrm{~km}$ northward in the upper $80 \mathrm{dbar}$ of this same region. More generally, these biases are quite small. The median correction for $\Theta$ is $1.0 \times 10^{-3}{ }^{\circ} \mathrm{C}$ on isopycnals. The median correction for $\Theta$ in the mixed layer $\left(1.1 \times 10^{-3}{ }^{\circ} \mathrm{C}\right)$ is only slightly larger.

\subsection{Back to Pressure Coordinates: Connecting the Mixed Layer and Interior Isopycnal Maps}

[42] Monthly maps of water properties in the mixed layer and on interior ocean isopycnals are products in their own

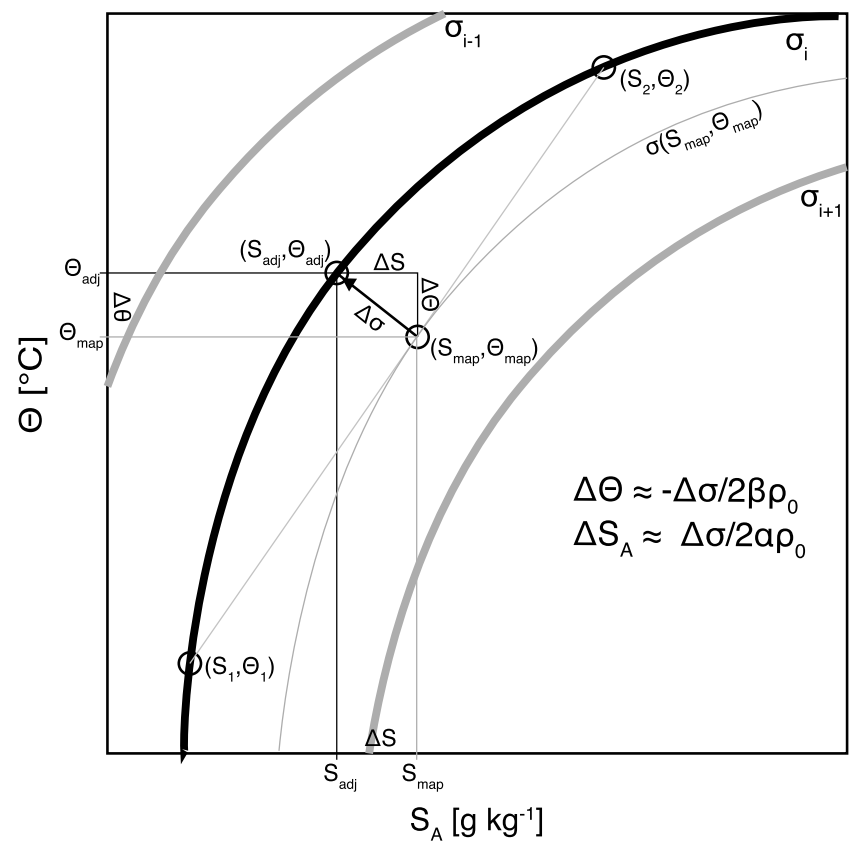

Figure 5. Schematic of artificial cabbeling in isopycnal mapping and its correction (see text for details). Points $\left(S_{1}, \Theta_{1}\right)$ and $\left(S_{2}, \Theta_{2}\right)$ represent raw data on an initial potential isopycnal $\sigma_{i},\left(S_{\text {map }}, \Theta_{\text {map }}\right)$ mapped values on a denser neutral surface, and $\left(S_{\text {adj }}, \Theta_{\text {adj }}\right)$ corrected/adjusted (and published) values back on the initial $\sigma_{i}$. The thermal expansion coeffient is $\alpha$, and the haline contraction coefficient is $\beta$. 


\section{a)}
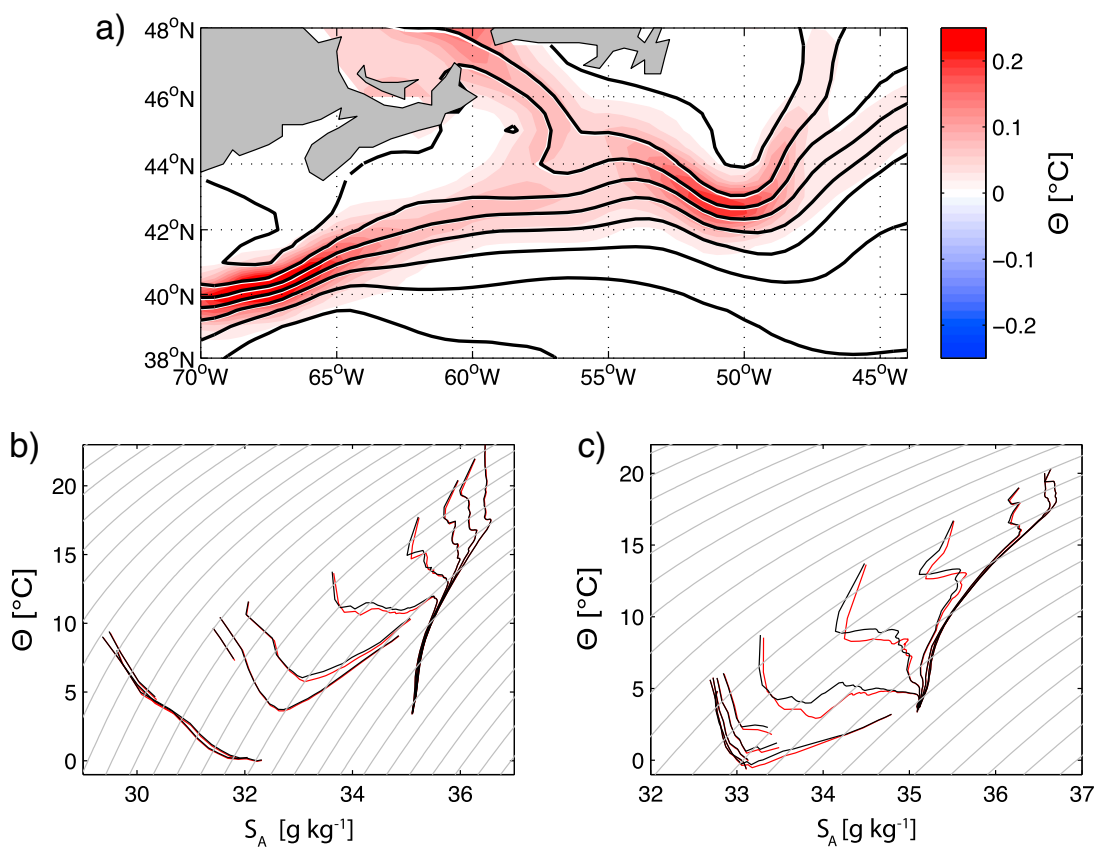

Figure 6. Map of (a) June conservative temperature $(\Theta)$ cabbeling corrections in mixed layer of the North Atlantic Current (color), isotherms contoured at $2{ }^{\circ} \mathrm{C}$ intervals, in the uncorrected (white) and corrected/adjusted (black) data set. Sets of $\Theta-S_{A}$ curves at $1^{\circ}$ latitude intervals for June over the upper $1500 \mathrm{dbar}$ at (b) $62.5^{\circ} \mathrm{W}$ and (c) $49.5^{\circ} \mathrm{W}$ showing uncorrected (red) and corrected (black) values.

right, but we also combine them onto a regular pressure grid for increased ease of use. This regridding is done at each geographical grid point and for each month. Mixed layer properties are assigned to all pressure grid points shallower than the local MLP. The MLP and interior ocean pressures at least $5 \mathrm{dbar}$ greater than the MLP and lower than the maximum possible bottom pressure are used to put $\theta$ and $S$ on a regular pressure grid via linear interpolation.

\section{Discussion}

[43] One advantage of isobaric mapping is that it is simple and can be performed over the whole water column. In contrast, isopycnal mapping requires the separate computation of the mixed layer, or a surface isobaric layer, for the reasons detailed below. This calculation can either be done by isobaric mapping down to a depth generally below the seasonal thermocline (e.g., WGHC) or by merging a separately mapped mixed layer to the interior ocean isopycnal maps, as done here. The isopycnal/mixed layer formulation has some very significant advantages over a simple isobaric mapping, for example, following water masses in the vertical, preserving vertical stratification, and enforcing hydrostatic stability (at least for the density parameter used to construct the climatology, in this case $\sigma_{0}$ ). The additions of front-sharpening and bathymetry-respecting algorithms add to those advantages. However, there are always trade-offs in constructing a climatology. One difficulty — biases in density resulting from artificial cabbeling owing to smoothing during the mapping process - has been previously recognized [e.g., Lozier et al., 1994, 1995] and discussed and dealt with above. In fact, that issue is probably larger in most isobaric climatologies, although efforts have been made to mitigate the artifacts [Locarnini et al., 2009; Antonov et al., 2009]. A remaining issue that merits further improvements, the difficulty of mapping near regions where isopycnals outcrop, is discussed at the end of this section.

\subsection{Mixed Layer}

[44] A mixed layer is often a desirable feature in a climatology. The mixed layer is in direct contact with the atmosphere, and water properties are by definition homogeneous there (in the ocean and in MIMOC, e.g., Figure 7). Resolving the seasonal cycle in the mixed layer, including dense, deep winter mixed layers, is crucial to water mass formation [e.g., Stommel, 1979). Thus, resolving the mixed layer and its temporal evolution in a climatology better allows the study of water mass formation using that climatology. For example, the evolution of a deep winter mixed layer is clear in MIMOC (Figure 7) within the formation regions for the South East Pacific Subtropical Mode Water (SEPSTMW) at $20.5^{\circ} \mathrm{S}$ and $99.5^{\circ} \mathrm{W}$, as expected from analyses of synoptic data [e.g., Wong and Johnson, 2003], but is less obvious in other climatologies (Figure 7). A global comparison of MIMOC maximum mixed layer depths with other commonly used mixed layer depths (Figure 8) shows MIMOC with sharper gradients between areas with deep and shallow maximum mixed layer within the course of the year. The mixed layer is also clear in vertical sections from synoptic data and MIMOC but is again less clearly defined in other climatologies (Figure 2).

\subsection{Isopycnal Mapping}

[45] Isopycnal maps better follow water parcels both laterally and vertically. One advantage of this tendency over isobaric maps is limiting the creation of artificial water masses found in climatologies smoothed on isobars [e.g., Lozier et al., 1994]. The smoothing effects on vertical density gradients by 

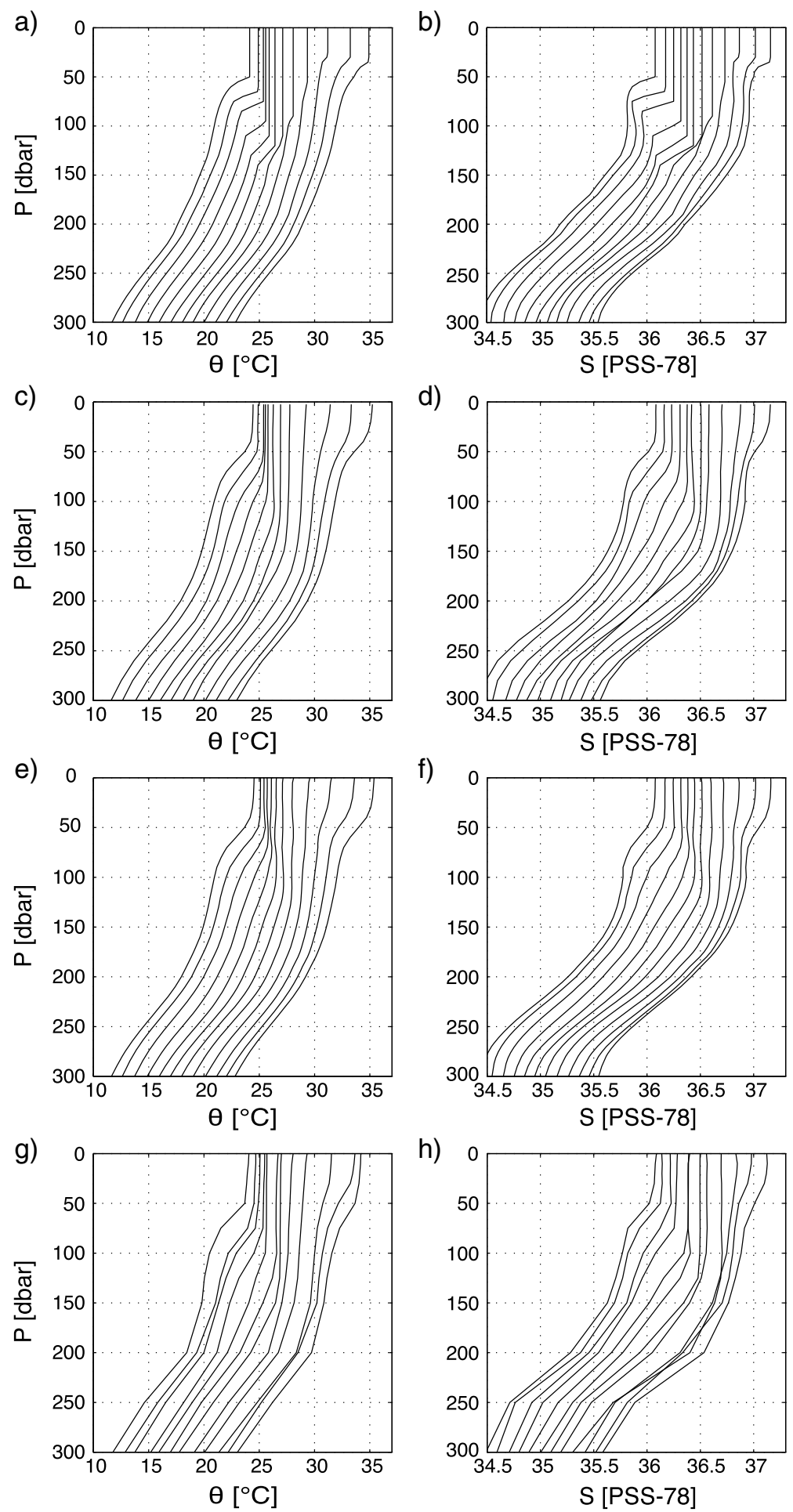

Figure 7. Temporal evolution over 12 months in the SEPSTMW formation region $\left(20.5^{\circ} \mathrm{S} 99.5^{\circ} \mathrm{W}\right)$ starting with the lightest ML in March for (a) $\theta$ and (b) $S$ in MIMOC offset by $1{ }^{\circ} \mathrm{C}$ and 0.1 PSS-78 per month, respectively, similar for (c-d) AMA, (e-f) CARS09, and (g-h) WOA09.

transient vertical excursions of isopycnals owing to planetary waves, internal waves, and tides are also greatly reduced in isopycnal maps relative to isobaric maps.

[46] For example, the strong and shallow pycnocline in the eastern equatorial Pacific undergoes substantial excursions owing to the seasonal cycle [e.g., Johnson et al., 2002] and also from Kelvin waves, Rossby waves, and ENSO [e.g., McPhaden and $Y u, 1999]$. In an isobaric average, these vertical excursions of isopycnals (along with those owing to eddies, internal waves, and tides) will tend to smear out the pycnocline in the vertical and reduce its magnitude substantially from what would be observed in a synoptic survey, as well as reduce the magnitude of $\Theta-S_{A}$ features within the pycnocline. As a result, 


\section{a) MIMOC}

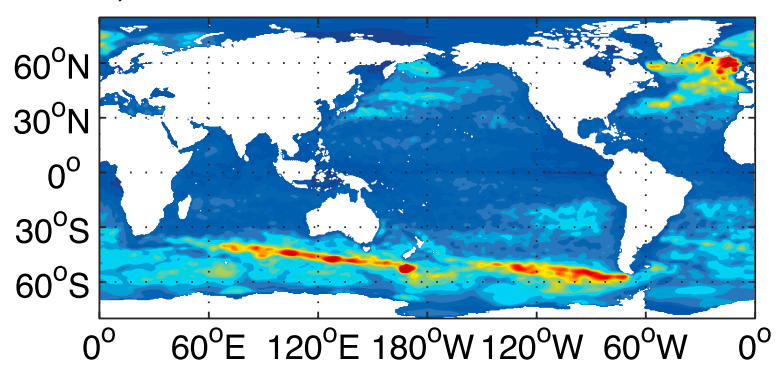

c) Holte et al. (2010)

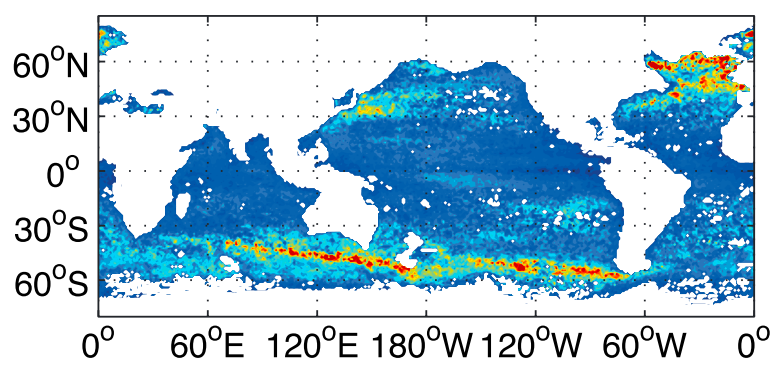

e) de Boyer Montégut et al. (2004)

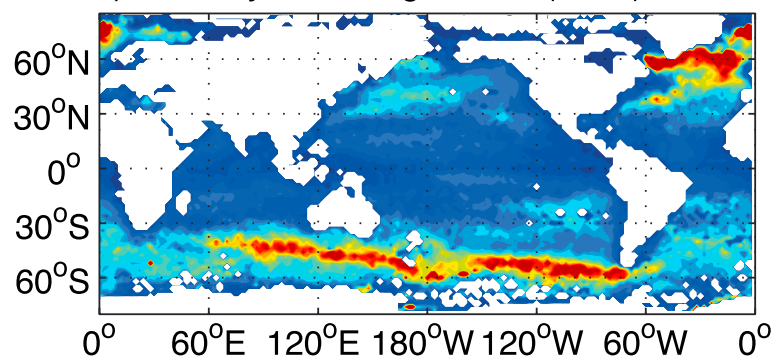

b) MIMOC (weighted mean, $\sigma_{0}$ threshold)

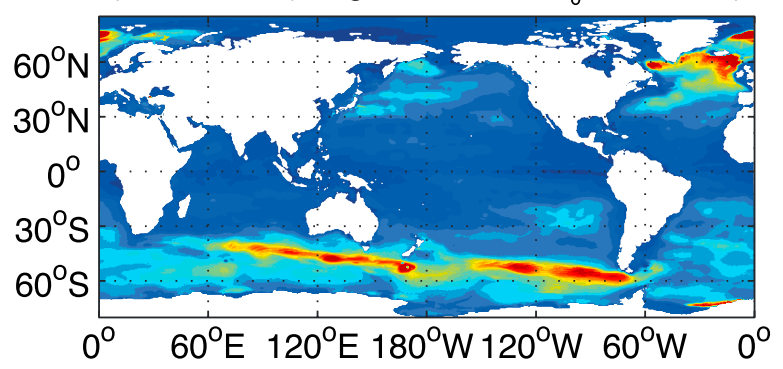

d) Helber et al. (2012)

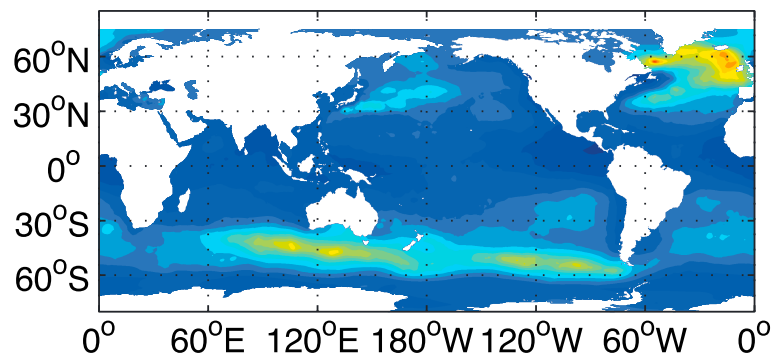

\section{f) CARSO9}

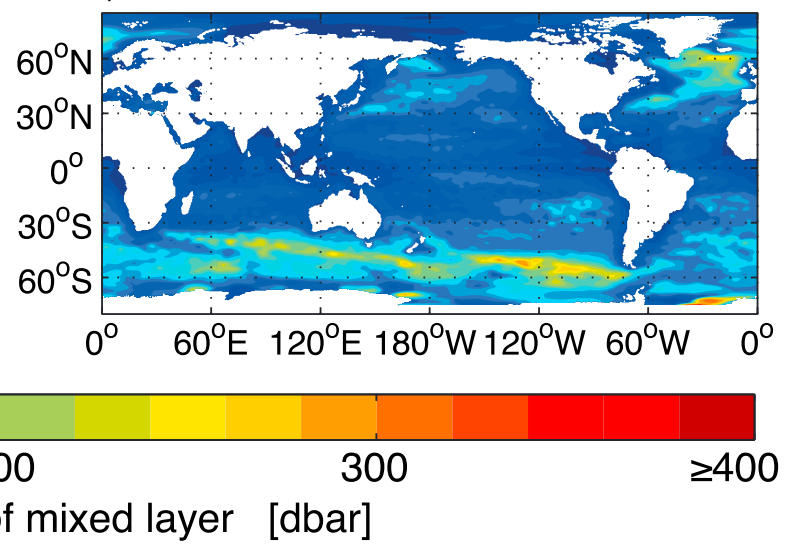

Figure 8. Maximum annual mixed layer depth from different climatologies. (a) MIMOC objective analysis of MLP determined by the Holte et al. [2009] density algorithm for individual profiles. (b) MIMOC weighted mean analysis MLP with density threshold of $0.03 \mathrm{~kg} \mathrm{~m}^{-3}$. (c) Holte et al. [2010] maximum recorded MLP by density algorithm within a $1^{\circ} \times 1^{\circ}$ bin. (d) Helber et al. [2012] maps. (e) de Boyer Montégut et al. [2004] temperature threshold. (f) CARS09 values.

MIMOC exhibits a much stronger and sharper pycnocline in this region than do other climatologies (as visualized by the squared Brunt-Väisälä frequency $-N^{2}$; Figure 9, right panels) and much better preserves the South Pacific salinity maximum and North Pacific salinity minimum that meet within the pycnocline at the equator (Figure 9, left panels) [e.g., Johnson and McPhaden, 1999].

\subsection{Isopycnal Boundary Problems}

[47] One aforementioned problematic issue with isopycnal mapping is that mapping errors which increase near the boundaries of the domain, where data are only available on one side of the mapped grid point, occur not only near coastlines and at the edges of data-sparse regions as they do for other maps, but also anywhere (or anytime) that the isopycnal outcrops in the ocean interior. On the other hand, the mixed layer (and any isobaric) maps do not have this source of uncertainty (and bias) in the ocean interior.

[48] Biases from this isopycnal mapping uncertainty should be most noticeable where the mixed layer meets interior ocean isopycnals in regions with large surface density gradients and limited data availability, for instance, in the Antarctic Circumpolar Current (Figure 10). The temperature inversion visible in MIMOC just below the mixed layer here may occur at least in part because the mixed layer map is constrained by both the colder, fresher water to the south and the warmer saltier water to the north, whereas the isopycnal maps near their surface outcrops would mostly (except for the upward profile extensions described above) see the warmer, saltier water to the north of the outcrop. Thus, the isopycnal maps could be biased toward those northern warm salty values, potentially creating the 

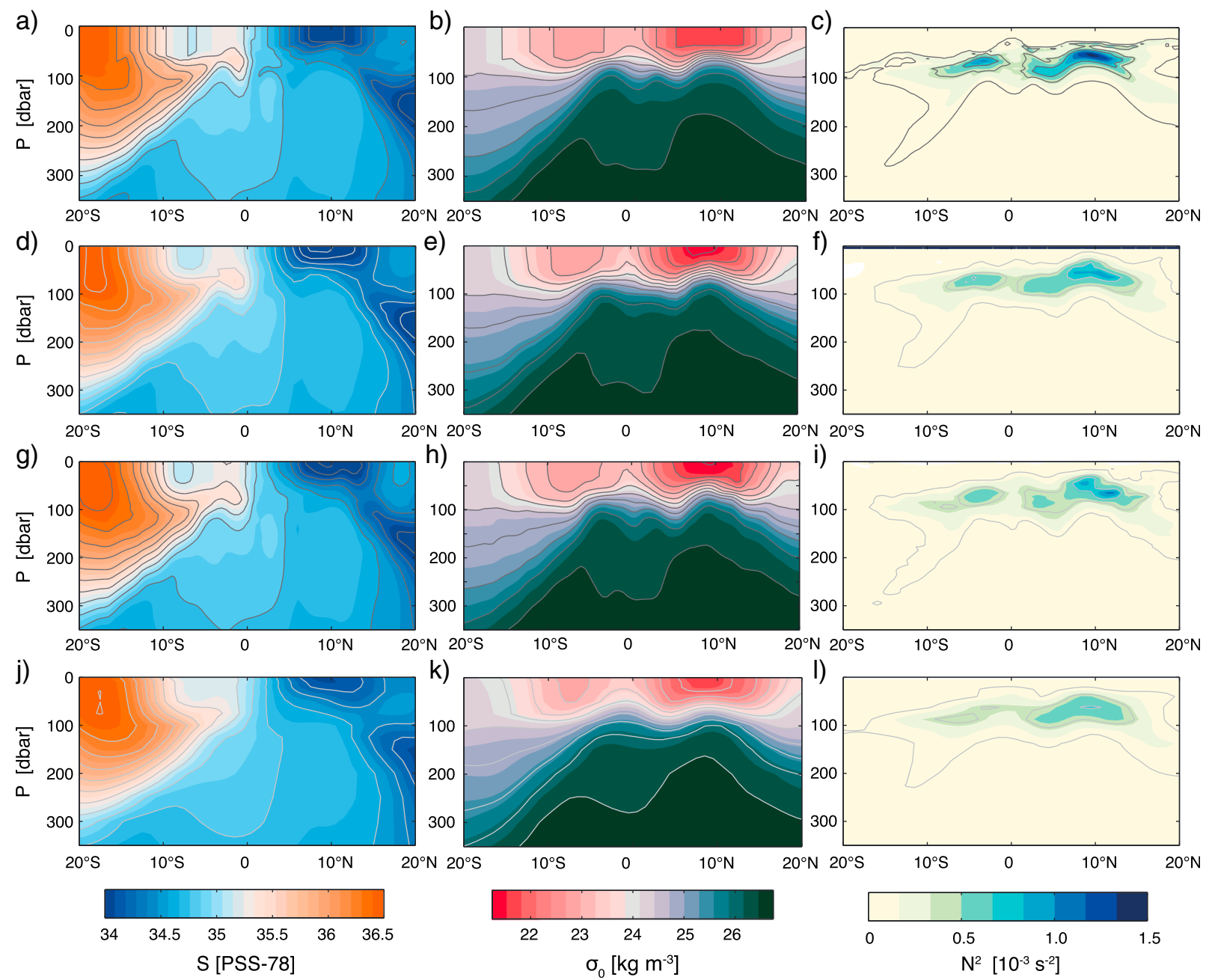

Figure 9. Meridional-vertical sections across the equatorial Pacific along $119.5^{\circ} \mathrm{W}$ in October of (left panels) $S$, (middle panels) $\sigma_{0}$, and (right panels) Brunt-Väisälä frequency squared, $N^{2}$, for (a-c) MIMOC, (d-f) AMA, (g-i) CARS09, and (j-1) WOA09. Isohalines are contoured at 0.2 PSS-78 intervals, isopycnals at $0.5 \mathrm{~kg} \mathrm{~m}^{-3}$ intervals, and isolines of $N^{2}$ at $0.3 \times 10^{-3} \mathrm{~s}^{-2}$ intervals starting at $0.1 \times 10^{-3} \mathrm{~s}^{-2}$. AMA maps for individual Octobers have a stronger pycnocline than the multi-October average shown here.

temperature inversion just below the mixed layer visible here or small discontinuities between the mixed layer and the ocean interior seen in other locations. This feature has been largely mitigated by the upward profile extension but is not completely resolved. However, what remains may also be realistic; some of the raw profiles in the region do display a temperature inversion similar to that found in the maps.

[49] A similar problem is found on dense isopycnals near $1800-2000 \mathrm{dbar}$, where the majority of data profiles used here end. In this instance, the densest isopycnals are observed by Argo only when they are shallower than average, whereas slightly lighter isopycnals are observed for their entire pressure range. Hence, the densest isopycnals are biased toward shallow pressures in the maps, creating artificially strong stratification just above 2000 dbar. Again, the extension described above reduces the impact of sudden drops in data density, but close to the bottom of the mapping ranges, values may be biased toward shallower depths and properties. For this reason, MIMOC is only published up to $1950 \mathrm{dbar}$ where this problem is still limited. To include the deeper oceans, MIMOC would need to be recomputed with full-depth CTD profiles only and then merged to the upper ocean climatology. While we plan to effect this improvement, it is not a simple task because a new problem of temporal discontinuities in full depth vs. upper ocean sampling arises.

\section{Summary}

[50] MIMOC is a monthly isopycnal/mixed-layer ocean climatology with three products: (1) mapped mixed layer properties ( $S$ and $\theta$, or $S_{A}$ and $\Theta$ with MLP), (2) mapped water properties $\left(S\right.$ and $\theta$, or $S_{A}$ and $\Theta$ with $P$ ) on selected potential density surfaces, and (3) water properties ( $S$ and $\theta$, or $S_{A}$ and $\Theta$ ) from the first two products merged onto a regular pressure grid. Numbers of weighted observations for the maps, the mapped dates, and formal mapping errors are provided for the mixed layer and isopycnal maps. The numbers of weighted observations for the maps and the mapped dates are also provided for the maps on the pressure grid. Smoother weighted mean fields are also provided. 

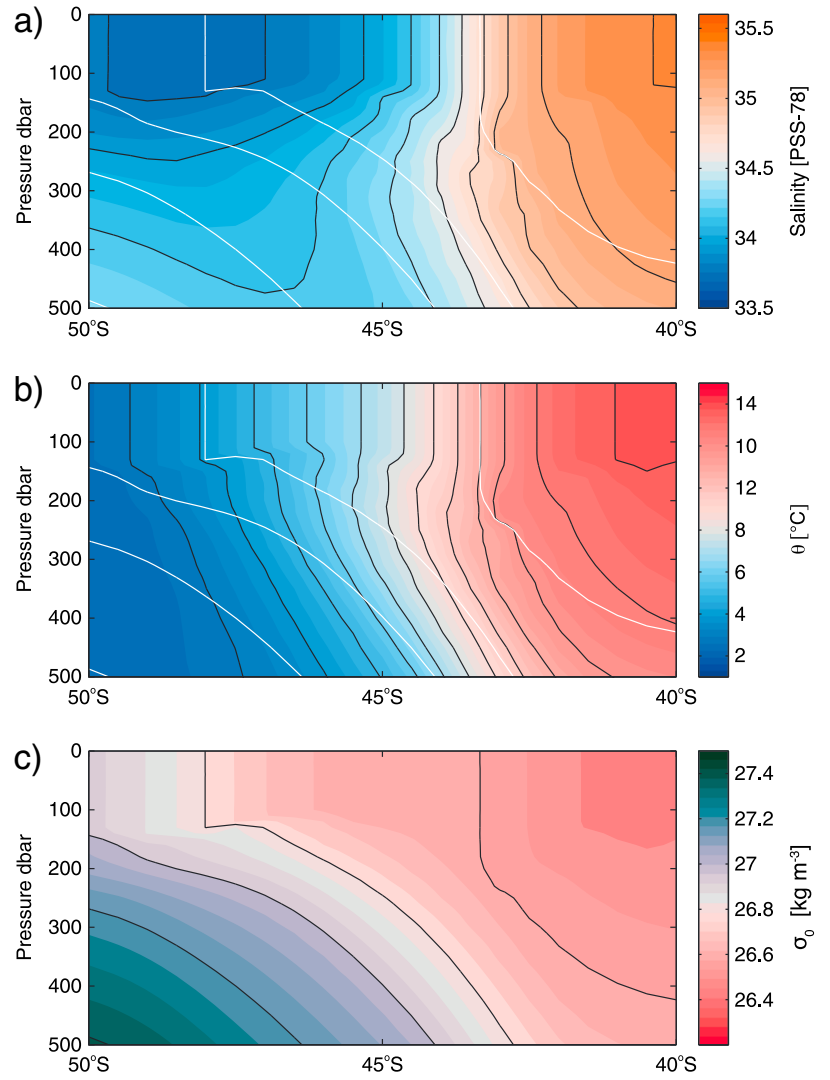

Figure 10. Meridional-vertical sections of MIMOC (a) $S$, (b) $\theta$, and (c) $\sigma_{0}$ along $60.5^{\circ} \mathrm{E}$ in September across the Antarctic Circumpolar Current. Isohalines are contoured at 0.2 PSS-78 intervals, isotherms at $1{ }^{\circ} \mathrm{C}$ intervals in their respective panels (black lines), and potential isopycnals (white lines in Figures 10a and 10b, black lines in Figure 10c) at $0.2 \mathrm{~kg} \mathrm{~m}^{-3}$ intervals.

[51] The goal of MIMOC is to make maps that preserve many of the features observed in a synoptic survey but minimizes the influences of eddies, planetary waves, internal waves and tides, and other transient phenomena. MIMOC preserves water mass properties both vertically and laterally; resolves boundary currents and shelf regimes (where data are available) while observing natural boundaries like land, inlets, islands, and ridges; accounts for the short meridional scales of the equatorial current systems; retains true mixed layers as well as preserving strong, sharp pycnoclines; and is stably stratified.

[52] To accomplish these goals MIMOC uses mapping mechanisms including combining mixed layer and interior isopycnal maps and employing front-sharpening algorithms that downweight profiles with regionally atypical characteristics and a "Fast Marching" algorithm that accounts for the influences of bathymetry and latitude (especially near the equator) on water property distributions. Comparing MIMOC in detail to other widely used climatologies suggests that MIMOC fulfills the goals listed above as well as or better than any of the comparison products.

[53] Isopycnal maps are more uncertain, and perhaps even biased near their surface outcrops, so joining the ocean interior to the surface mixed layer in MIMOC is not free from difficulty, especially in regions of large surface density gradients and sparse data distributions. However, procedures are applied that largely mitigate this problem and a similar one near the bottom of the climatology. Residual mismatches may still result in small temperature inversions or other discontinuities.

[54] MIMOC could not be constructed without a highquality, temporally and spatially well-sampled set of profiles of contemporaneously measured temperature and salinityArgo. Improvements could include extending MIMOC to the deep ocean, adding data in remote regions, mapping water mass properties in addition to $S_{A}$ and $\Theta$ (or $S$ and $\theta$ ), and developing a more sophisticated method for matching mixed layer and isopycnal properties at outcrop locations.

\section{Appendix A: Data Access}

[55] The climatology is currently hosted at http://www. pmel.noaa.gov/mimoc/ as well as on a European server. All files are provided in netCDF format, and mixed layer files are additionally available in geotiff format. Each parameter is available as gridded objectively mapped fields as well as smoother gridded weighted mean fields (see manuscript for description).

[56] Global 0-1950 dbar pressure-gridded monthly fields of potential temperature and practical salinity, conservative temperature and absolute salinity, mapped time (in year) of data (see manuscript for description), and the sums of data weights are all available for download.

[57] The above parameters are also available on selected isopycnal levels from the bottom of the mixed layer to $1950 \mathrm{dbar}$, further including the pressures of these isopycnals.

[58] Mixed layer files contain the mixed layer depth (more accurately the maximum mixed layer pressure) and other parameters listed above, as computed by the Holte et al. [2009] algorithm and mapped as described in the text.

[59] As MIMOC develops, further files and parameters may be added.

[60] Acknowledgments. We thank all those who participated in the collection, calibration, and assembly of the shipboard (http://www.nodc. noaa.gov/OC5/WOD09/pr_wod09.html), Argo, and ITP CTD data used here. The Ice-Tethered Profiler data were collected and made available by the Ice-Tethered Profiler Program based at the Woods Hole Oceanographic Institution (http://www.whoi.edu/itp). Argo float profile data were collected and made freely available by the International Argo Project and the national programs that contribute to it (http://www.argo.ucsd.edu). We thank Ruth Curry and four anonymous reviewers for their helpful comments on drafts of the manuscript. The research presented in this paper was carried out on the High Performance Computing Cluster supported by the Research and Specialist Computing Support service at the University of East Anglia. The NOAA Climate Program Office and NOAA Research supported this work. PMEL contribution 3805. Pacific Marine Environmental Laboratory contribution 3805 .

\section{References}

Amante, C., and B. W. Eakins (2009), ETOPO1 1 Arc-Minute Global Relief Model: Procedures, Data Sources and Analysis, NOAA Technical Memorandum NESDIS NGDC-24, 19 pp., U.S. Government Printing Office, Washington, D.C.

Antonov, J. I., D. Seidov, T. P. Boyer, R. A. Locarnini, A. V. Mishonov, H. E. Garcia, O. K. Baranova, M. M. Zweng, and D. R. Johnson (2010), World Ocean Atlas 2009, Volume 2: Salinity, edited by S. Levitus, 
NOAA Atlas NESDIS 69, 184 pp., U.S. Government Printing Office, Washington, D.C.

Bainbridge, A. E. (1976), GEOSECS Atlantic Expedition, Sponsored by International Decade of Ocean Exploration, National Science Foundation, U.S. Government Printing Office, Washington, D.C.

Boyer, T. P., et al. (2009), World Ocean Database 2009, edited by S. Levitus, NOAA Atlas NESDIS 66, U.S. Gov. Printing Office, Wash. D.C., DVDs. 2

Bretherton, F., R. Davis, and C. Fandry (1976), A technique for objective analysis and design of oceanographic experiments applied to MODE73, Deep-Sea Res., 23, 559-582, doi:10.1016/0011-7471(76)90001-2.

Cleveland, W. S. (1981), LOWESS: A program for smoothing scatterplots by robust locally weighted regression, The American Statistician, 35, 54.

Coachman, L. K. (1986), Circulation, water masses, and fluxes on the southeastern Bering Sea Shelf, Cont. Shelf Res., 5, 23-108, doi: 10.1016/0278-4343(86)90011-7.

Curry, R. G. (1996), HydroBase: A Database of Hydrographic Stations and Tools for Climatologic Analysis, WHOI Technical Report 96-01, 55 pp.

de Boyer Montégut, C., G. Madec, A. S. Fischer, A. Lazar, and D. Iudicone (2004), Mixed layer depth over the global ocean: An examination of profile data and a profile-based climatology, J. Geophys. Res., 109, C12003, doi:10.1029/2004JC002378.

Deacon, G. E. R. (1937), The hydrology of the Southern Ocean, Discovery Reports, 15, 124.

Dijkstra, E. W. (1959), A note on two problems in connexion with graphs, Numerische Mathematik, 1, 269-271, doi:10.1007/BF0138639.

Flament, P. (2002), A state variable for characterizing water masses and their diffusive stability: Spiciness, Prog. Oceanogr., 54, 493-501, PII S0079-6611(02)00065-4, doi:10.1016/S0079-6611(02)00065-4.

Fuglister, F. C. (1960), Atlantic Ocean Atlas of Temperature and Salinity Profiles and Data from the International Geophysical Year of 19571958, Woods Hole Oceanographic Institution Atlas Series, 1, Woods Hole, Massachusetts, 209 pp.

Gille, S. T. (2004), How nonlinearities in the equation of state of seawater can confound estimates of steric sea level change, J. Geophys. Res., 109, C03005, doi:10.1029/2003JC002012.

Gordon, A. L. (1966), Potential temperature, oxygen and circulation of bottom water in the Southern Ocean, Deep-Sea Res., 13, 1125-1138, doi:10.1016/0011-7471(66)90704-2.

Gouretski, V., and K. Koltermann (2004), WOCE Global Hydrographic Climatology, Berichte des BSH, 35, 52 pp., ISSN: 0946-6010.

Helber, R. W., A. B. Kara, J. G. Richman, M. R. Carnes, C. N. Barron, H. E. Hurlburt, and T. Boyer (2012), Temperature versus salinity gradients below the ocean mixed layer, J. Geophys. Res., 117, C05006, doi:10.1029/ 2011JC007382.

Holte, J., and L. Talley (2009), A new algorithm for finding mixed layer depths with applications to Argo data and Subantarctic Mode Water formation, $J$. Atmos. Oceanic Tech., 26, 1920-1939, doi:10.1175/2009JTECHO543.1.

Holte, J., J. Gilson, L. Talley, and D. Roemmich (2010), Argo mixed layers, Scripps Institution of Oceanography/UCSD, http://mixedlayer.ucsd.edu, August 2012.

IOC, SCOR and IAPSO, (2010), The International Thermodynamic Equation of Seawater - 2010: Calculation and Use of Thermodynamic Properties, Intergovernmental Oceanographic Commission, Manuals and Guides No. 56, UNESCO (English), 196 pp.

Johnson, G. C., and M. J. McPhaden (1999), Interior pycnocline flow from the subtropical to the equatorial Pacific Ocean, J. Phys. Oceanogr., 29, 3073-3089, doi:10.1175/1520-0485(1999)029 < 3073:IPFFTS > 2.0.CO;2.

Johnson, G. C., B. M. Sloyan, W. S. Kessler, and K. E. McTaggart (2002), Direct measurements of upper ocean currents and water properties across the tropical Pacific Ocean during the 1990's, Prog. Oceanogr., 52, 31-61, PII S0079-6611(02)00021-6, doi:10.1016/S0079-6611(02)00021-6.

Johnson, G. C., P. J. Stabeno, and S. D. Riser (2004), The Bering Slope Current system revisited, J. Phys. Oceanogr., 34, 384-398, doi:10.1175/1520-0485(2004)034<0384:TBSCSR > 2.0.CO;2.

King, B. A., E. Firing, and T. M. Joyce (2001), Shipboard Observations during WOCE, in Ocean Circulation and Climate: Observing and
Modelling the Global Ocean, vol. 77, edited by G. Siedler et al., International Geophysics, pp. 99-122, Academic Press.

Klatt, O., O. Boebel, and E. Fahrbach (2007), A profiling float's sense of ice, J. Atmos. Oceanic Tech., 24, 1301-1308, doi:10.1175/JTECH2026.1.

Locarnini, R. A., A. V. Mishonov, J. I. Antonov, T. P. Boyer, H. E. Garcia, O. K. Baranova, M. M. Zweng, and D. R. Johnson (2010), World Ocean Atlas 2009, Volume 1: Temperature, edited by S. Levitus, 184 pp., NOAA Atlas NESDIS 68, U.S. Government Printing Office, Washington, D.C.

Lozier, M. S., M. S. McCartney, and W. B. Owens (1994), Anomalous anomalies in averaged hydrographic data, J. Phys. Oceanogr., 24, 2624-2638, doi:10.1175/1520-0485(1994)024 < 2624:AAIAHD > 2.0.CO;2.

Lozier, M. S., W. B. Owens, and R. G. Curry (1995), The climatology of the North Atlantic, Prog. Oceanogr., 36, 1-44, doi:10.1016/0079-6611(95) 00013-5.

McDougall, T. J. (1987), Thermobaricity, cabbeling, and water-mass conversion, J. Geophys. Res., 92, 5448-5464, doi:10.1029/JC092iC05p05448.

McDougall, T. J., and D. R. Jackett (2005), The material derivative of neutral density, J. Mar. Res., 63, 159-185, 10.1357/0022240053693734.

McPhaden, M. J., and X. Yu (1999), Equatorial waves and the 1997-98 El Niño, Geophys. Res. Lett., 26, 2961-2964, doi:10.1029/1999GL004901.

Murray J. (1885), A Summary of the Scientific Results, Challenger Reports, $1608 \mathrm{pp}$.

Nansen, F. (1900), The Norwegian North Polar Expedition, 1893-1896: Scientific Results, vol. 1-6, edited by F. Nansen, Fridtjof Nansen Fund for the Advancement of Science.

Pedlosky, J. (1987), Geophysical Fluid Dynamics, 710 pp., Springer-Verlag, New York.

Pytkowicz, R. M. (1968), Water Masses and their Properties at $160^{\circ} \mathrm{W}$ in the Southern Ocean, J. Oceanogr. Soc. Japan, 24(1), 21-31.

Ridgway K. R., J. R. Dunn, and J. L. Wilkin (2002), Ocean interpolation by four-dimensional least squares -Application to the waters around Australia, J. Atmos. Ocean. Tech., 19, 1357-1375, doi:10.1175/1520-0426 (2002) $019<1357$ :OIBFDW $>2.0 . \mathrm{CO} ; 2$

Roemmich, D., and J. Gilson (2009), The 2004-2008 mean and annual cycle of temperature, salinity, and steric height in the global ocean from the Argo Program, Prog. Oceanogr., 82, 81-100, doi:10.1016/j. pocean.2009.03.004.

Roemmich, D., G. C. Johnson, S. Riser, R. Davis, J. Gilson, W. B. Owens, S. L. Garzoli, C. Schmid, and M. Ignaszewski (2009), The Argo Program: Observing the global ocean with profiling floats, Oceanogr., 22(2), 34-43, doi:10.5670/oceanog.2009.36.

Rudnick, D. L., and R. Ferrari (1999), Compensation of horizontal temperature and salinity gradients in the ocean mixed layer, Science, 283, 526-529, doi:10.1126/science.283.5401.526.

Schmidtko, S., and G. C. Johnson (2012), Multidecadal warming and shoaling of Antarctic Intermediate Water, J. Climate, 25, 207-221, doi:10.1175/JCLI-D-11-00021.1.

Sethian, J. A. (1996), A fast marching level set method for monotonically advancing fronts, Proc. Nat. Acad. Sci., 93, 1591-1595, doi:10.1073/ pnas.93.4.1591

Sethian, J. A. (1999), Fast marching methods, SIAM Review, 41, 199-235.

Stommel, H. (1979), Determination of water mass properties of water pumped down from the Ekman layer to the geostrophic flow below, Proc. Natl. Acad. Sci., 76, 3051-3055, doi:10.1073/pnas.76.7.3051.

Toole, J. M., R. A. Krishfield, M.-L. Timmermans, and A. Proshutinsky (2011), The Ice-Tethered Profiler: Argo of the Arctic, Oceanogr., 24(3), 126-135, doi:10.5670/oceanog.2011.64.

Tsuchiya, M., L. D. Talley, and M. S. McCartney (1994), Water-mass distributions in the western South Atlantic; A section from South Georgia Island (54S) northward across the equator, J. Mar. Res., 52, 55-81, doi: $10.1357 / 0022240943076759$.

Wong, A. P. S., and G. C. Johnson (2003), South Pacific Eastern Subtropical Mode water, J. Phys. Oceanogr., 33, 1493-1509, doi:10.1175/1520-0485(2003)033<1493:SPESMW > 2.0.CO;2.

Wüst, G., and A. Defant (1936), Schichtung und Zirkulation des Atlantischen Ozeans. Wiss. Ergebn. Dt. Atlant. Exped. "Meteor" 1925-1927, Bd. VI, Atlas, 103 pp. 